\title{
Science in Strasbourg and the Success of E-MRS
}

I recently traveled to Strasbourg as an official MRS representative, along with Rod Ewing of the University of New Mexico, to the 1989 Spring Meeting of the European Materials Research Society (E-MRS). A detailed technical report of the meeting will be published in an upcoming issue of the MRS BULLETIN. In this short letter, however, I would like to share with you what I consider to be some of the exciting developments of E-MRS.

This E-MRS Spring Meeting hosted more than 650 participants, double the size of the same meeting I attended in 1986. Each of the five technical symposia (ranging from silicon molecular beam epitaxy to biomaterials) was well attended, with poster sessions on different days. There were also literature displays as well as some equipment exhibits. The format closely resembled that of an MRS meeting.

There were, however, some notable differences at this E-MRS meeting. One of them was the special, attentive Europeanstyle atmosphere offered during the meeting. Because the meeting was held at the Council of Europe, the rooms were extremely comfortable with large, softcushioned seats and earphones, much like the United Nations. All those who preregistered for the-E-MRS meeting found their final program materials already waiting at their hotels. On each of the four days, attendees were treated to a threecourse lunch featuring fine Strasbourg cuisine, including both white and red wines. On Wednesday night, all $600+$ participants were taken to a nearby winery for a three-hour dinner party. Some 60 people enjoyed the party so much that they missed the bus and stayed there until 2 a.m.!

The other major difference was that not
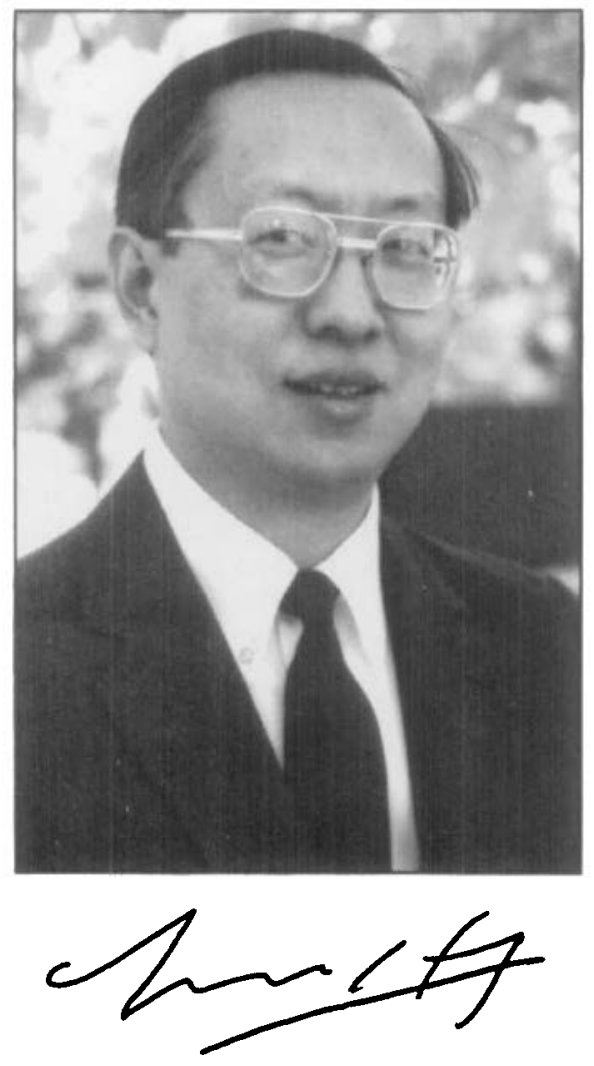

only was the meeting multidisciplinary in nature, but it was also truly multinational. At any one meal, I found myself sitting with people from three or four different countries. In addition to attending some of the most interesting technical talks that resulted from this international gathering of scientists, I was also able to attend the EMRS delegates meeting and other meetings at which arrangements for future cosponsorship of international meetings were already under discussion.

\section{Planning for the Future}

Since its start in 1983, E-MRS has been managed and led by a group of dedicated European scientists, with Prof. Siffert as president. It was only a few years ago that E-MRS became a formally registered society. Last year, the Society elected its first board of delegates from the 12 European Community countries. The delegates were in the process of meeting to formally elect the members of the E-MRS executive committee. An announcement of the new $\mathrm{E}$ MRS officers will be made in an upcoming issue of the MRS BULLETIN.

Each of their new delegates (near 50 strong) has, or will be assigned, to oversee specific societal projects such as education, programming, external affairs, industrial relations, etc. What is of interest to me is their $16+$ E-MRS networks which oversee different areas of materials research in Europe. I have great admiration for these hard-working individuals.

With a membership of over 1,100, E-MRS is currently being run entirely by volunteers, much like the early days of the Materials Research Society when volunteers spent a great deal of their time working for the Society.

And E-MRS's hard work has already paid off! Today, E-MRS is a muchrespected society in Europe helping to serve the materials community of the EC countries. I am highly impressed by the enthusiasm with which the delegates work together in an ever growing society. On behalf of MRS, I wish E-MRS continued success and prosperity.

R.P.H. Chang

\section{Highlights from the 1989 MRS Spring Meeting in San Diego ...see p. 54.}

